\title{
PENINGKATAN NILAI TAMBAH HASIL PERKEBUNAN NILAM DI DESA BONE-BONE KEC. BARAKA KABUPATEN ENREKANG
}

\author{
Nunuk Hariani Soekamto, Firdaus, Yusafir Hala, dan Amirullah Dachlan \\ Universitas Hasanuddin \\ E-mail: nunukhariani@unhas.ac.id
}

\begin{abstract}
ABSTRAK. Sulawesi Selatan termasuk salah satu sasaran produksi minyak nilam tertinggi secara nasional pada tahun 2018 selain Sulawesi Tengah, dan Sumatera Barat. Kabupaten Enrekang yang termasuk dalam wilayah Sulawesi Selatan telah membudidayakan pohon nilam dan juga memproduksi minyak nilam. Produksi minyak nilam tersebut belum mendapatkan hasil secara maksimal baik disegi rendemen maupun kualitas minyaknya dimana kandungan Patchouli Alkoholnya yang masih relatif rendah. Untuk mengatasi hal tersebut maka dilakukan kegiatan Pengabdian kepada Masyarakat. Tujuan Pengabdian ini adalah untuk menjadikan masyarakat petani nilam dapat memroduksi minyak dengan kandungan Patchouli alcohol yang cukup tinggi (kualitas tinggi) dan rendemen yang tinggi pula. Hal ini dapat meningkatkan penghasilan dan sekaligus membantu dalam memenuhi sasaran produksi minyak nilam tertinggi secara nasional tahun 2018. Metode yang telah dilakukan adalah memberikan penyuluhan tentang cara persemaian, pengolahan tanah, penanaman dan pemeliharaan, serta pemanenan dan prapengolahannya. Untuk tahun pertama telah dilakukan penyuluhan dan pelatihan cara pembibitan yang sesuai dengan standard serta pengukuran kromatogram menggunakan Kromatografi Gas agar diketahui kandungan Patchouli alcohol pada minyak nilam yang dihasilkan. Hasil yang diperoleh dari kegiatan ini adalah masyarakat menjadi tahu cara budidaya tanaman nilam yang baik. Selain itu diketahui juga kandungan Patchouli alcohol dari minyak nilam hasil panen petani nilam sebesar 24,86 \%. Setelah petani paham cara budidaya nilam, maka produksi minyak nilam khususnya di Kabupaten Enrekang akan meningkat kandungan Patchouli alkoholnya sampai mencapai target minimal 30\% dan menjadi berkualitas ekspor.
\end{abstract}

Kata kunci: Budidaya; minyak nilam; Patchouli alcohol

\section{INCREASING VALUE ADDED RESULT OF Patchouli PLANTATION IN VILLAGE BONES, KEC. BARAKA DISTRICT ENREKANG}

\begin{abstract}
South Sulawesi was one of the highest national patchouli oil production targets in 2018 besides Central Sulawesi and West Sumatra. Enrekang Regency which is included in the South Sulawesi region has cultivated patchouli trees and also produced patchouli oil. Patchouli oil production has not gotten maximum results both in terms of yield and quality of oil where the content of Patchouli Alcohol is still relatively low. To overcome this, community service activities are carried out. This service aim is to make farming community able to produce oil with a fairly high Patchouli alcohol content (high quality) and yield. This can increase income and at the same time help meet the highest patchouli oil production target nationally in 2018. The method that has been carried out is to provide counseling on how to nursery, land management, planting, and maintenance, as well as harvesting and pre-processing. For the first year, counseling and training in nursery methods were carried out by following the standards and chromatogram measurements using Gas Chromatography to determine Patchouli alcohol content in the resulting patchouli oil. The results obtained from this activity are that the community knows how to cultivate patchouli plants properly. Also known as the Patchouli alcohol content of patchouli oil yielded by farmers is $24.86 \%$. After farmers understand how to patchouli cultivation, patchouli oil production, especially in Enrekang Regency will increase its Patchouli alcohol content to reach the target of at least $30 \%$ and become export quality.
\end{abstract}

Keywords: Cultivation, patchouli oil, Patchouli alcohol

\section{PENDAHULUAN}

Nilam sebagai salah satu minyak atsiri unggulan di Indonesia telah memberikan pangsa pasar lebih dari $90 \%$ kebutuhan dunia atau sekitar $35-40 \%$ dari total nilai ekspor minyak atsiri. Produksi yang baik dapat mencapai 15-20 ton daun basah atau 5 ton daun kering per ha dengan rendemen minyak 2,5-4\% sehingga produksi minyak mencapai 100-200 kg/ha/tahun (Emmyzar dan Ferry 2004).

Indonesia merupakan produsen minyak nilam terbesar di dunia, namun Indonesia tidak banyak memiliki industri yang menggunakan minyak nilam karena kurangnya modal dan teknologi yang terbatas, sehingga produksi minyak nilam menjadi penting untuk diekspor kenegara-negara maju yang memiliki kekuatan industri dan teknologi seperti Amerika Serikat dan Perancis.
Permintaan dunia terhadap minyak nilam juga sangat tinggi seperti Singapura, Amerika Serikat, Spanyol dan Perancis. Mengingat negara-negara tersebut memiliki teknologi industri yang sangat baik dan mempunyai modal yang banyak.

Singapura menduduki peringkat pertama tujuan ekspor minyak nilam Indonesia sebesar 31,17\%, kemudian Amerika Serikat sebesar 17,92\%, Spanyol sebesar 16,4\%, dan Perancis sebesar 8,85\% (Ditjenbun-Balittro, 2008).

Negara-negara tersebut mengimpor minyak nilam, karena minyak nilam sangat baik digunakan untuk industri parfum dan kosmetika. Minyak nilam adalah satusatunya minyak atsiri yang memiliki Pachouli Alcohol berguna untuk memfiksasi parfum agar wanginya lebih tahan lama. Sistem penjualan minyak nilam Indonesia sangat bergantung pada harga minyak nilam di pasaran dunia. Hal ini juga didukung oleh penelitian Sari 
(2009) menyebutkan bahwa harga ekspor minyak nilam Indonesia mengikuti perkembangan harga internasional. Zakiah 2000) menyebutkan bahwa harga minyak nilam di pasaran dunia ini sangat responsif terhadap volume ekspor minyak nilam. Hal ini dikarenakan harga internasional minyak nilam menganut pada harga di negara Perancis. Perancis lebih selektif dalam mengimpor minyak nilam, berbeda dengan Singapura dan Amerika Serikat yang yang selama ini lebih mengimpor minyak nilam kasar, Perancis hanya mengimpor minyak nilam dengan mutu yang tinggi dan bebas dari kandungan besi.

Ekspor Minyak Nilam Indonesia Tahun 20072011 (ton/tahun) dengan nilai juta US\$, pada tahun 2007 sebesar 1.309 ton - nilai 48,66 juta \$; tahun 2008 sebesar 1.242 ton - 80,29 juta \$; tahun 2009 sebesar 1.516 ton 44,32 juta\$; tahun 2010 sebesar 1.540 ton - 58,89 juta\$; tahun 2011 sebesar 1.567 ton - 71,93 juta\$ (Sumber: Kemenperin, 2016)

Berdasar data Produksi Komoditas Utama Perkebunan Tahun 2010-2014 Renstra Kementerian Pertanian Tahun 2015-2019, diketahuai produksi Nilam tahun 2010 sebesar 2.206 ton, dan pada tahun 2014 telah meningkat sebesar 2.690 ton, dengan rata-rata pertumbuhan 5,97\%/ tahun selama 5 tahun. Produksi nilam ini sebanding dengan naiknya jumlah luas areal komoditas Nilam yakni pada tahun 2010 luas areal Nilam 24.472 ha, dan pada tahun 2014 telah menjadi seluas 31.288 ha, dengan kenaikan rata-rata pertahun 5,10\%/tahun selama 5 tahun.

Sasaran produksi nilam untuk tahun 2016 di pulau Jawa, angka tertinggi adalah Jawa Barat sebesar 0,248 (ribu ton), Jawa Timur sebesar 0,240 (ribu ton), Jawa Tengah sebesar 0,203 (ribu ton), dan DIY sebesar 0,012 (ribu ton). Sedangkan DKI Jakarta, dan Banten nihil. Sasaran produksi secara nasional pada tahun 2016 tertinggi ada di Sulawesi Selatan, Sulawesi Tengah, dan Sumatera Barat.

Sasaran produksi minyak nilam tersebut memberikan peluang yang cukup besar bagi petani di Sulawesi Selatan khususnya di Kabupaten Enrekang.

Ditinjau dari aspek produksi minyak nilam sangat tergantung pada cara budidaya serta kualitas bibit yang digunakan. Sudaryani dan Sugiharti 1991 mengatakan bahwa Budidaya yang sederhana dan kurang intensif serta bibit yang kurang baik mutunya menyebabkan produktivitas nilam menjadi rendah, yaitu sekitar 2 ton daun nilam kering/ha/tahun. Hal ini dialami pula oleh Kelompok Tani Putra Koro I yang memproduksi minyak nilam di Desa Bone-Bone Kec. Baraka Kab. Enrekang. Kementrian perdagangan telah berupaya untuk memberikan penyuluhan dan memfasilitasi peralatan untuk mendapatkan minyak nilam. Namun beberapa alat belum pernah digunakan karena pemahaman masyarakat tentang budidaya dan pengolahannya masih kurang. Selain itu tanaman nilam tidak bias dipanen beberapa kali sebagaimana mestinya.

Berdasarkan hal tersebut maka telah dilakukan kegiatan PkM dengan tujuan menjadikan masyarakat petani nilam dapat paham cara pembibitan dan penanaman nilam baik dan sesuai standar,

\section{METODE}

Langkah-langkah yang ditempuh sebagai metode pelaksanaan Pengabdian Kepada Masyarakat ini adalah sebagai berikut:

a. Identifikasi permasalahan, pertemuan sebagian tim dengan petani nilam Kelompok Tani Putra Koro I Desa Bone-Bone Kec. Baraka Kab. Enrekang. Identifikasi masalah dilakukan dengan cara survey dan wawancara. Survey dilakukan ke para petani nilam di Desa Bone-Bone Kecamatan Baraka Kabupaten. Adapun pengumpulan data melalui wawancara, dilakukan secara terbuka terhadap beberapa orang nara sumber

b. Penyuluhan yang dilakukan kepada petani nilam yaitu Kelompok Tani Putra Koro I Desa Bone-Bone Kec. Baraka Kab. Enrekang agar paham tentang apa saja yang harus diperhatikan dalam bertanam nilam.

c. Penyuluhan tentang manfaat minyak nilam bagi kesehatan.

d. Memberikan pelatihan tentang tatacara pembibitan nilam di Desa Bone-Bone Kec. Baraka Kab. Enrekang sampai bisa panen.

e. Mengekstrak minyak nilam (skala laboratorium) di Laboratorium Kimia Organik Departemen Kimia FMIPA Unhas.

f. Menguji minyak nilam yang dihasilkan dibandingkan dengan standar/database Patchouli alkohol menggunakan instrument Kromatografi Gas (GC) dan Spektroskopi Massa (MS)

g. Melalui Kromatogram GC, dihitung secara kuantitatif kandungan Patchouli alkohol pada minyak nilam

\section{HASIL DAN PEMBAHASAN}

Berdasarkan analisis situasi baik yang terdapat pada masyarakat petani nilam maupun situasi akan kebutuhan pasar sebagaimana yang telah diuralkan di atas, telah dipetakan beberapa permasalahan mitra yang terkait dengan peningkatan produksi nilam dan produksi minyak nilam di Kabupaten Enrekang.

Pertumbuhan pohon nilam yang kurang baik yang otomatis mempengaruhi produksi nilam Hasil olahan nilam yang menghasilkan minyak nilam dengan kualitas yang rendah.

Permasalahan diatas sangat mempengaruhi kondisi Kabupaten Enrekang secara umum. Hal ini bisa kita lihat dari berapa banyak lahan yang belum maksimal dimanfaatkan. Apabila lahan tersebut sudah tergarap semua dengan hasil yang signifikan maka selain masyarakat Tani nilam menjadi lebih sejahtera, pendapatan daerahpun akan semakin meningkat. Dengan demikian dapat mendukung peningkatan baik di bidang pendidikan maupun bidang pertanian. 
Diskusi yang dilakukan pada saat diadakan penyuluhan dan pelatihan terlihat sangat aktif karena para petani sangat ingin memperbaiki kebun mereka. Pengabdian ini dilakukan dengan tidak sia-sia. Para petani juga sangat ingin untuk bisa menanam pohon nilam dengan baik dan benar. Disini letak peran serta tim Unhas melakukan pengabdian kepada Masyarakat petani nilam. Keterkaitan tani nilam dengan tujuan pembangunan wilayah sebagai berikut:

Meningkatkan diversifikasi produk pertanian, khususnya sub sektor perkebunan. Industri nilam dapat membuka lapangan kerja baru sebagai nilai tambah yang dapat dinikmati oleh warga desa. Secara umum hal ini dapat meningkatkan pendapatan dan kesejahteraan petani, berkontribusi terhadap Produk Domestik Regional Bruto (PDRB) daerah, sekaligus menjadi jalan untuk promosi daerah.

Kesesuaian lahan untuk pengembangan nilam memberikan peluang untuk melakukan rotasi tanaman, sebagai usaha menekan perkembangan organisme pengganggu tanaman (OPT) dan mensiasati pasar produk pertanian yang sangat fluktuatif.

Perkebunan nilam yang dikelola dengan baik, intensif, kontinyu, maka bisa menambah daftar produk unggulan Kabupaten Enrekang selain bawang merah, kopi dan sayuran dataran tinggi.

Hasil diskusi memperlihatkan bahwa tanaman nilam tidak dapat dipanen sesuai yang seharusnya (sampai 3 tahun) karena kekurangan unsur hara. Selain itu jarak tanam yang belum sesuai dengan yang semestinya. Untuk itu sangat diperlukan pendampingan dilakukan secara intensif kepada petani nilam. Hasil penyuluhan yang telah dilaksanakan oleh Tim PkM menambah pemahaman para petani tentang tatacara penanamam nilam yang benar. Hal ini terlihat dari diskusi yang panjang dan penuh antusias. Penyuluhan lain juga dilakukan dihari berikutnya tentang manfaat minyak nilam di bidang kesehatan dan dari penyuluhan ini ternyata masyarakat tani baru mengerti bahwa banyak manfaat minyak nilam untuk kesehatan. Pada Kegiatan PkM ini dilakukan pelatihan tatacara pembibitan yang benar dan dalam beberapa waktu kemudian mempraktekannya.

Kesuburan tanaman juga sangat mempengaruhi hasil minyak nilam, dengan kenyataan kandungan PAnya sebesar 24,86\%, sedangkan standar minimal kandungan PA minyak nilam yang berkualitas yaitu $30 \%$.

\section{SIMPULAN}

Pada Program pengabdian yang dilakukan sampai dengan tahap akhir kegiatan 2018 ini telah menyelesaikan penyuluhan cara budi daya nilam yang sesuai standar, pelatihan tatacara pembibitan dan penyuluhan yang terkait dengan manfaat minyak nilam di bidang kesehatan yang cukup menambah pemahaman para petani mengenai hal tersebut.

\section{UCAPAN TERIMA KASIH}

Ucapan terima kasih ditujukan kepada Universitas Hasanuddin yang telah mendanai kegiatan Pengabdian kwpada Masyarakat melalui hibah internal.

\section{DAFTAR PUSTAKA}

Emmyzar dan Yulius Ferry. 2004. Pola Budidaya untuk Peningkatan Produktivitas dan Mutu Minyak Nilam. Perkembangan Teknologi TRO Vol. XVI, No.2: 52-61

Ditjenbun-Balittro. 2008. Standar Prosedure Operasional Budidaya Tanaman Nilam. Direktorat Budidaya Tanaman Semusim Kerjasama dengan Balai Penelitian Tanaman Obat dan Aromatik. 41 hlm.

Kemenperin, 2016. Pengembangan Ekspor kelompok minyak atsiri.

Rosman, R.,Suryadi, R., Djazuli, M., Sudiman, A. dan Setiawan, 2016. Pengaruh pola tanam terhadap pertumbuhan, produksi dan usahatani nilam, Bul. Littro, Volume 27, Nomor 1, 19-26

Sudaryanti, T dan Sugiharti, E. 1990. Budidaya dan Penyulingan Nilam. Penebar Swadaya. Jakarta. Balittro, 2012

Sari, P.N. dan Hartono, S., 2010. Analisis Dinamika Ekspor Minyak Nilam Indonesia ke Amerika Serikat, Agro Ekonomi, Vol. 17 No. 1, 19 - 28

Zakiah (2000). Model Respon Produksi dan Ekspor Minyak Nilam Indonesia, Suatu Analisis Simulasi, Tesis tidak diterbitkan, Program Pascasarjana Institut Pertanian Bogor 